\title{
Kinase and Phosphatase Activities Intimately Associated with a Reconstituted Calcium-Dependent Potassium Channel
}

\author{
Peter H. Reinhart ${ }^{1}$ and Irwin B. Levitan ${ }^{2}$ \\ 'Department of Neurobiology, Duke University Medical Center, Durham, North Carolina 27710 and 'Biochemistry \\ Department and Center for Complex Systems, Brandeis University, Waltham, Massachusetts 02254
}

\begin{abstract}
Type-2 calcium-dependent potassium $\left(K_{\mathrm{ca}}\right)$ channels from mammalian brain, reconstituted into planar phospholipid bilayers, are modulated by ATP or ATP analogs via an endogenous protein kinase activity intimately associated with the channel (Chung et al., 1991). We show here that the endogenous protein kinase activity is protein kinase $\mathrm{C}$ (PKC)-like because (1) modulation by ATP can be mimicked by exogenous PKC, and (2) the effects of ATP can be blocked by $\mathrm{PKC}_{(19-36)}$, a specific peptide inhibitor of PKC. Furthermore, adding the PKC inhibitor peptide after the addition of ATP reverses the modulation produced by ATP, suggesting that there is a phosphoprotein phosphatase activity closely associated with type- $2 \mathrm{~K}_{\mathrm{ca}}$ channels. Consistent with this idea is the finding that microcystin, a nonspecific phosphatase inhibitor, enhances the modulation of $K_{\mathrm{Ca}}$ channel activity by ATP. Inhibitor-1, a specific protein inhibitor of phosphoprotein phosphatase-1, also enhances the effect of ATP, suggesting that the endogenous phosphatase activity is phosphatase-1-like. The results imply that type-2 $\mathrm{K}_{\mathrm{ca}}$ channels exist as part of a regulatory complex that includes a PKC-like protein kinase and a phosphatase-1-like phosphoprotein phosphatase, both of whIch participate in the modulation of channel function.
\end{abstract}

[Key words: $\mathrm{Ca}^{2+}$-activated $\mathrm{K}^{+}$channels, modulation, protein kinases, protein phosphatases, phosphorylation, lipid bilayers, protein complexes, ion channels]

The modulation of membrane ion channels is central to neuronal function. Most (if not all) ion channels are subject to modulation, often as a result of phosphorylation at serine, threonine or tyrosine residues within the sequence of the ion channel protein itself (reviewed in Levitan, 1994). The widespread existence of such regulatory sites suggests that modulation by phosphorylation may be an essential inherent property of many voltage-gated (Catterall, 1993) and ligand-gated (Raymond et al., 1993) ion channels.

We have been investigating the modulation, by phosphorylation, of large conductance calcium-dependent potassium $\left(\mathrm{K}_{\mathrm{Ca}}\right)$

\footnotetext{
Received Aug. 22, 1994: revised Dec. 2, 1994; accepled Dec. 23, 1994.

This work was supported by NIH Grant NS.3125.3 to P.H.R. and grants to I.B.L. from the NIH and the Bristol-Myers Squibb Company. I.B.L. also acknowledges generous support for the Center for Complex Systems from the $W$. M. Keck Foundation. Some of these experiments were performed at the Marine Biological Laboratory in Woods Hole, MA. We are grateful to Dr. Larry Kat/ and Timothy DiChiara for their critical comments on the manuscript.

Correspondence should be addressed to Dr. Peter H. Reinhart, Department of Neurobiology, DUMC, Box 3209, Duke University Medical Center, Durham, NC 27710

Copyright 1995 Society for Neuroscience $0270-6474 / 95 / 154572-(08 \$ 05.00 / 0$
}

channels from the mammalian brain (Reinhart et al., 1991; Chung et al., 1991). Specific functions of these channels in the nervous system include the setting of neuronal firing frequencies (Lancaster et al., 1991), participation in neuropeptide secretion (White et al., 1991: Bielefeldt and Jackson, 1994a), and regulation of presynaptic calcium signals and neurotransmitter release (Robitaille and Charlton, 1992). Using planar bilayer reconstitution techniques, we have identificd two distinct types of large conductance $K_{c a}$ channel in membrane vesicles from rat cortex (Reinhart et al., 1989). Channels with similar properties have also been identified using patch-clamp techniques (Wang et al., 1992; Bielefeldt and Jackson, 1994a). These channels have similar single channel conductances, but differ in their kinetics. pharmacology and modulation by the catalytic subunit of the cAMP-dependent protein kinase (PKA) (Reinhart et al., 1989: Reinhart et al., 1991). In addition, one of these channels, which we have named the type- $2 K_{c a}$ channel, can be modulated by ATP alone without the addition of exogenous protein kinase (Chung et al., 1991). This effect of ATP requires protein phosphorylation by an endogenous protein kinase activity that remains intimately associated with the type- $2 \mathrm{~K}_{\mathrm{ca}}$ channel in the planar bilayer.

The phosphorylation state of any protein represents an equilibrium between opposing protein kinase and phosphoprotein phosphatase activities. Most studies to date have focused on protein kinases as channel modulators, and it is only recently that the crucial role of phosphatases in neuromodulatory phenomena in general, and ion channel modulation in particular, has begun to be appreciated (Reinhart et al., 1991; White et al., 1991; Byrne et al., 1993; White et al., 1993; Wilson and Kaczmarek, 1993; Bielefeldt and Jackson, 1994a). We show here that there is also a phosphoprotein phosphatase activity that remains closely associated with the type- $2 \mathrm{~K}_{\mathrm{C}}$ channel in the planar bilayer. and that this activity can be blocked by a specific protein inhibitor of phosphoprotein phosphatase-1. In addition, we provide pharmacological evidence that the endogenous protein kinase activity associated with the channel is protein kinase $\mathrm{C}$ (PKC)like. Thus, the type- $2 \mathrm{~K}_{\mathrm{Ca}}$ channel from rat brain can exist as part of a regulatory complex that includes not only the ion channel itself, but also a specific complement of enzymatic activities that modulate its function.

\footnotetext{
Materials and Methods

Membrane vesicle preparation. Rat brain plasma membrane vesicles were prepared essentially as described previously (Reinhart et al., 1989. 1991). Briefly, rat cortex was excised and immediately homogenized in an ice-cold isotonic sucrose buffer (in mM: 250 sucrose, $2.5 \mathrm{KCl}, 0.1$ EGTA, 0.1 EDTA, 0.1 dithiothreitol, 20 IIEPES, pH 7.2). The homogenate was centrifuged at $2500 \times g$ for $3 \mathrm{~min}$, the pellet washed once.
} 

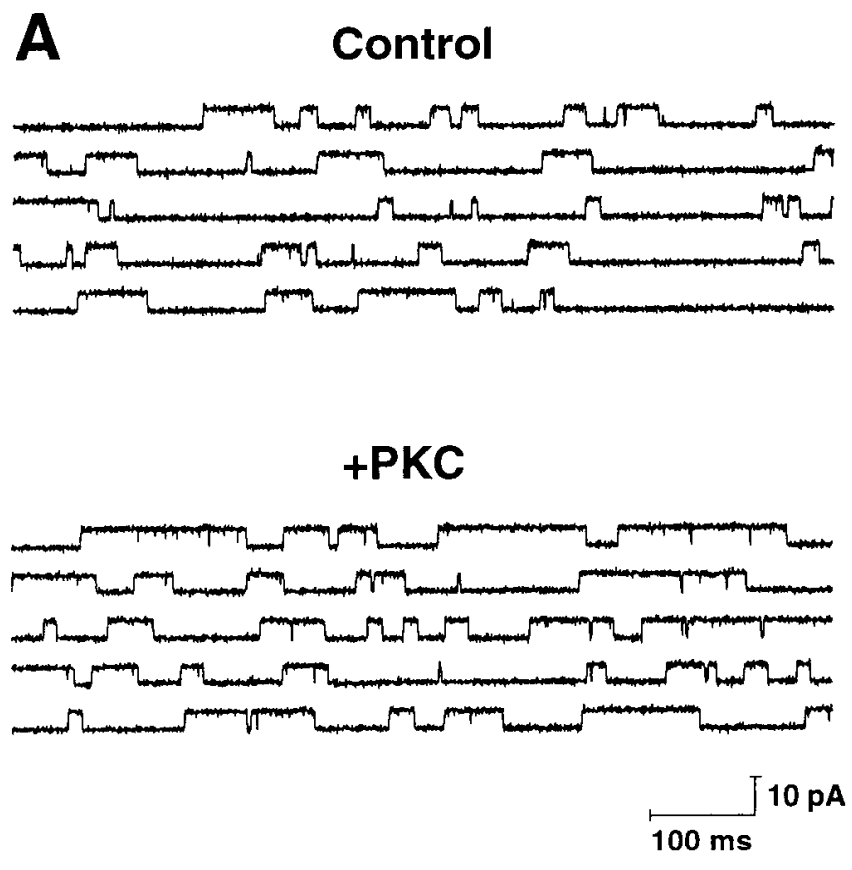

B

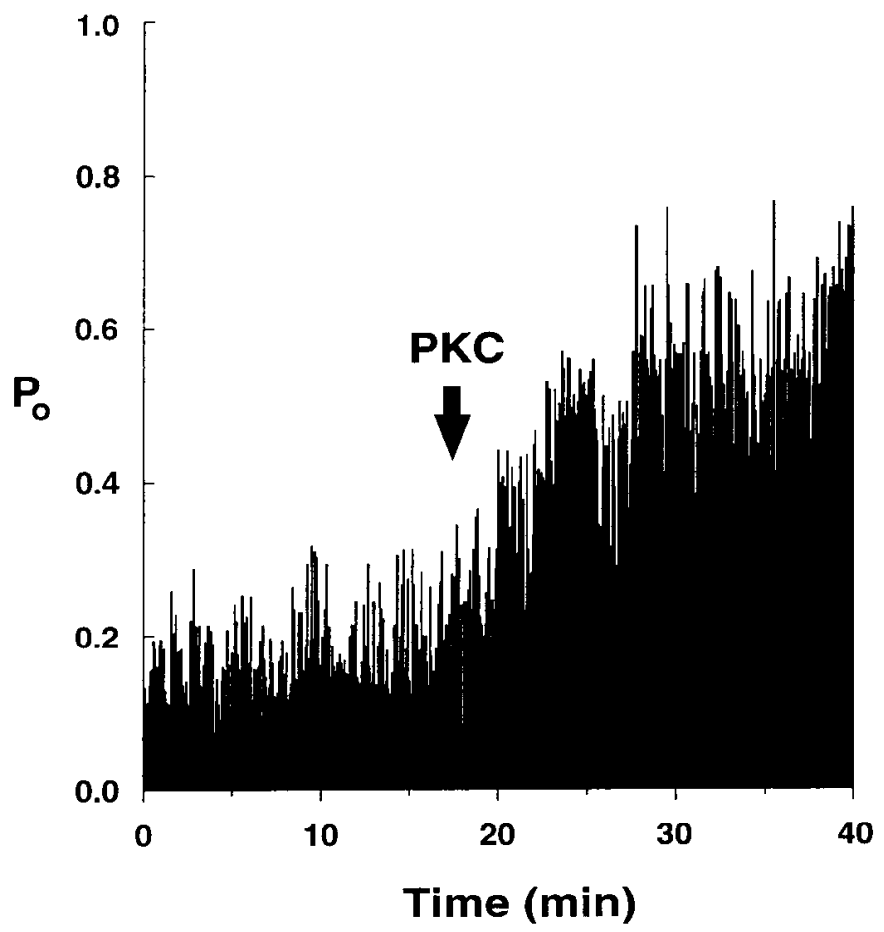

Figure 1. Activation of a single type-2 large-conductance $\mathrm{Ca}^{2+}$-activated $K^{*}$ channel in lipid bilayers by exogenously added PKC. The transmembrane voltage was clamped to $+10 \mathrm{mV}$, and the reversal potential for $\mathrm{K}^{\text {}}$ was set to $-28 \mathrm{mV}$. For all traces channel openings are shown as upward deflections from the closed level current. A:Control, Single channel gating in the presence of $0.1 \mathrm{~mm}$ ATP just prior to the addition of $\mathrm{PKC}+P K C$, Single channel gating 3 min after the addition of $25 \mathrm{nM}$ PKC to the cytoplasmic side of the ion channel. $B$, The time course of PKC-induced changes in the open probability of the same channel shown in $A$. The channel open probability was calculated continuously. and each vertical line represents the average for a $5.12 \mathrm{sec}$ and the combined supernatants were centrifuged at $30,000 \times g$ for 10 min. The resulting pellet was resuspended in a hypotonic lysis buffer (in mm: 0.1 dithiothreitol, $2.5 \mathrm{KCl}, 5$ Tris- $\mathrm{HCl}, \mathrm{pH} 8.2$ ) and allowed to stand on ice for $20 \mathrm{~min}$. The isotonic sucrose buffer and the lysis buffer both contaned $20 \mu \mathrm{g} / \mathrm{ml}$ trypsin inhibitor and aprotinin. The membranes were than rehomogenized, repelleted, and layered under a discontinuous step gradient of Percoll $(25,18,10$, and $0 \%: v / v)$. The gradient was centrifuged at $45,000 \times g$ for $2 \mathrm{~min}$, and the membrane fraction banding at the $0-10 \%$ Percoll interface was collected. The Percoll was removed by high-speed centrifugation, and the plasma membranes were stored at $-80^{\circ} \mathrm{C}$.

Bilayer reconstitution and single channel recording. Single channel recordings were made following fusion of these plasma membrane fractions with planar lipid bilayers (Coronado and Latorre, 1982; Miller, 1986). Membranes were added to the cytoplasmic side of the bilayer chamber, which contained cytoplasmic solution (in $\mathrm{mM}: 150 \mathrm{KCl}, 1.05$ $\mathrm{CaCl}_{2}, 1$ EGTA, $1 \mathrm{MgCl}_{2}, 7 \mathrm{KOH}, 10 \mathrm{HEPES}, \mathrm{pH} 7.4$ ). The free calcium ion concentration was adjusted by the addition of $\mathrm{CaCl}_{2}$ or EGTA, and calculated using the program EQCAL. (Biosoft, Cambridge. UK) using previously published stability constants. The extracellular solution contained (in mM) 0.1 EGTA, $7 \mathrm{KOH}, 10 \mathrm{HEPES}(\mathrm{pH} 7.4) . \mathrm{K}_{(: 1}$ channels insert into the bilayer predominantly in one direction, with the intracellular calcium-sensing side facing the solution into which the vesicles were added. Of the two large conductance $\mathrm{K}_{\mathrm{c}_{1}}$ channels in this preparation (Reinhart et al., 1989), only the charybdotoxin-insensitive, slower gating type- 2 channel was studied in these experiments; the activity of the faster gating type-1 channel is not affected by ATP in the absence of exogenous protein kinase (Reinhart et al.. 1991). Occasionally a membrane vesicle preparation contained channels that could not be modulated by ATP or any kinase or phosphatase tested ( 3 of 19 preparations); we do not know the basis for this variability. After incorporation of a channel into the bilayer, further fusion was suppressed by adding $50 \mathrm{~mm} \mathrm{KCl}$ to the extracellular chamber to reduce the transmembrane osmotic gradient. Single channel currents were recorded with an Axopatch 200 patch-clamp amplifier (Axon Instruments, Foster City. CA) or a BC-525A Bilayer Clamp (Warner Instruments, Camden, CT). The data were filtered at $1 \mathrm{kHz}$ using an eight-pole Bessel filter, and digitized at $4 \mathrm{kHz}$ for analysis. Voltages are expressed using cellular convention, that is the voltage of the cytoplasmic side relative to that of the extracellular side. Single channel records were idealized using baseline tracking and a $50 \%$ threshold crossing algorithm using custom software. Idealized data records were analyzed using PCLAMPG (Axon Instruments), Transit (obtained from Dr. Antonius VanDongen. Duke University Medical Center), and custom software.

Reagents. PKC $\mathrm{C}_{112,36,}, \mathrm{R} 27 \mathrm{E}-\mathrm{PKC} \mathrm{C}_{19,36,1}$, and microcystin-LR were obtained from GIBCO-Bethesda Research Labs. Rat brain PKC was purified by the method of Woodgett and Hunter (1987). The thiophosphorylated form of inhibitor-1 was generously provided by Dr. Angus Nairn (Rockefeller University, NY). After thiophosphorylation the inhibitor was purified by ion exchange chromatography to remove any residual ATP $\gamma$ S. ATP, 1-oleoyl-2-acetyl-sn-glycerol (OAG) and all other chemicals were obtained from Sigma.

\section{Results}

$P K C$ increases the open probability of type-2 $K_{c \text { a }}$ channels The open probability of the type- $2 \mathrm{~K}_{\mathrm{Ca}}$ channel from rat brain is increased by $\Lambda T P$ and ATP analogs, via the action of an endogenous protein kinase activity that is closely associated with the channel (Chung et al., 1991). As a first step towards characterization of this endogenous protein kinase, we determined the effects of several exogenous protein kinases on channel activity. The catalytic subunit of PKA, in the presence of low concentrations of ATP $(0.1 \mathrm{~mm})$, causes a decrease in the open probability of this channel (Reinhart et al., 1991), and thus it seems unlikely that the endogenous kinase activity is PKA-like. On the other hand, purified PKC that has been activated by diacylglycerol can increase the type- 2 channel open probability

$\leftarrow$

sweep. PKC ( 25 nM) was added at $17 \mathrm{~min}($ arrow). The data shown are from one of seven independent experiments performed. 

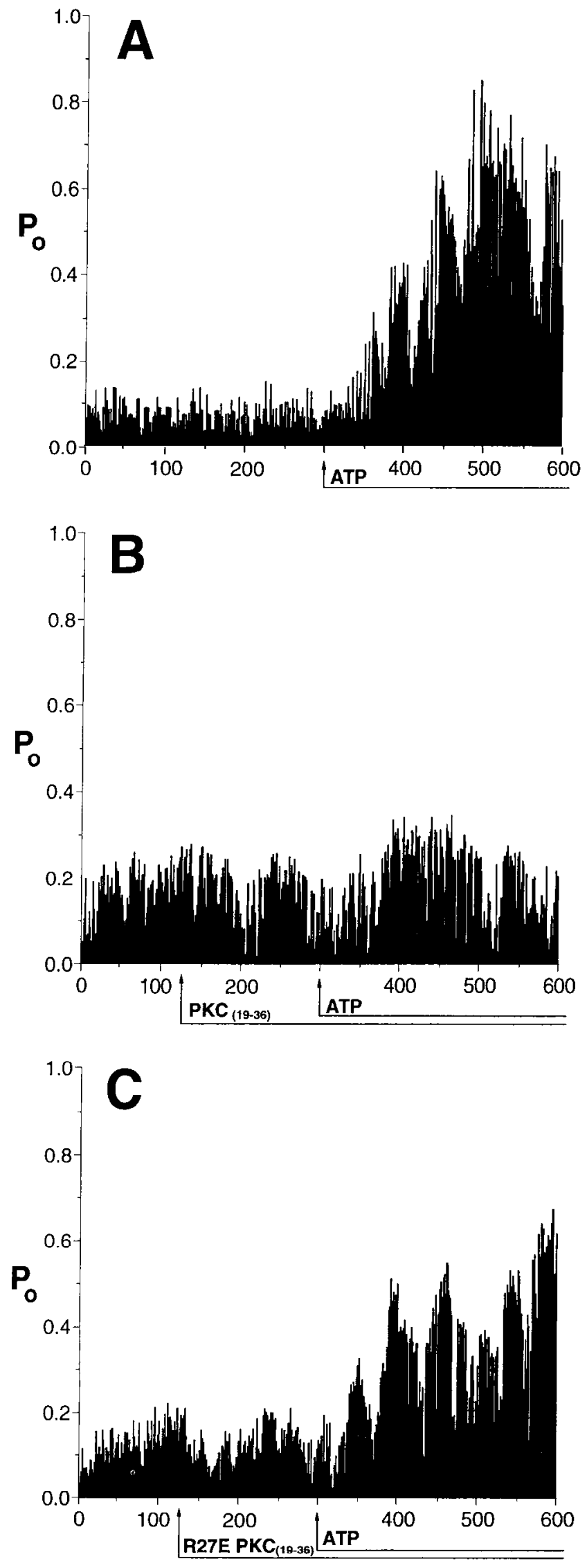

Time (sec) over and above the increase caused by low concentrations $(0.1$ mM) of ATP alone (Fig. $1 ; n=7$ ). The top traces in Figure $1 A$ (control) illustrate the activity of a single type- 2 channel in the presence of $100 \mu \mathrm{M}$ ATP; the open probability under these conditions oscillated between 0.15 and 0.3 , and was on average approximately two- to threefold higher than in the absence of ATP. Addition of PKC (25 nM) in the presence of $1 \mu \mathrm{M} 1$-oleoyl2-acetyl-sn-glycerol (OAG; Fig. $1 A$, bottom traces) causes an additional increase in open probability, characterized by both an increase in mean channel open time and a decrease in mean closed time (data not shown). PKC increased the open probability from 2.6 to 5.2-fold in seven to nine independent experiments performed. The time course of the action of PKC (Fig. $1 B$ ) illustrates that the increase in open probability occurs gradually over a period of many minutes, suggesting that multiple phosphorylation events may contribute to the modulation of channel aclivity.

\section{A PKC inhibitor blocks the modulation by ATP}

The finding that PKC modulates type-2 channel activity in the same direction as ATP is consistent with the possibility that the endogenous kinase activity is PKC-like. In order to test this further, we asked whether an inhibitor of PKC can block the action of ATP. Amino acid residues $19-36$ of brain PKC comprise a pseudosubstrate autoinhibitory domain, and a synthetic peptide $\left(\mathrm{PKC}_{(14-36)}\right)$ corresponding in sequence to this domain is a potent and specific inhibitor of PKC (House and Kemp, 1987). As described previously (Chung et al., 1991) AIP causes an increase in the open probability of more than $60 \%$ ( 12 of 19 experiments) of all type-2 $\mathrm{K}_{\mathrm{C}: \mathrm{i}}$ channcls incorporated into lipid bilayers (Fig. $2 A)$. This action of ATP is blocked by pretreatment of the channel with $\mathrm{PKC}_{(19-36)}$ (Fig. $2 B$; six of six experiments), strongly suggesting that the endogenous protein kinase that mediates the action of ATP is indeed PKC-like in its pharmacology. To test for the specificity of this block, an inactive analog of $\mathrm{PKC}_{(1)-301}$ was used. The arginine residue at position 27 of $\mathrm{PKC}$ is essential for autoinhibition, and a synthetic peptide in which this arginine is changed to a glutamate residue ( $\left.\mathrm{R} 27 \mathrm{E}-\mathrm{PKC}_{(19-3)}\right)$, although very similar in structure to the parent peptide, docs not inhibit PKC activity (House and Kemp, 1987). Pretreatment of the type-2 channel with R27E-PKC $\left(19-x_{1}\right.$ does not block the increase in open probability evoked by ATP (Fig. $2 C$; four of four experiments), confirming that the block by $\mathrm{PKC}_{(19-36)}$ results from specific inhibition of a PKC-like activity rather than from nonspecific side effects.

\section{$\leftarrow$}

Figure 2. Activation of a type-2 large-conductance $\mathrm{Ca}^{2+}$-activated $\mathrm{K}$ channel in lipid bilayers by $\Lambda$ TP and inhibition of this effect by the protein kinase $\mathrm{C}$ inhibitory peptide $\mathrm{PKC}_{11036}$. The recording conditions are as in Figure 1. The channel open probability was adjusted to between 0.05 and 0.15 using either $\mathrm{CaCl}_{2}$ or EGTA. The channel open probability was calculated continuously, and each vertical line represents the average for a $2.56 \mathrm{sec}$ sweep. A, ATP $(0.5 \mathrm{~mm})$ was added to the cytoplasmic side of the channel $300 \mathrm{sec}$ after starting the recordings. The data shown are from one of 12 independent experiments performed. $B, \mathrm{PKC}_{(1 \%-36)}(0.2 \mu \mathrm{M})$ was added to the cytoplasmic side of the channel at $120 \mathrm{sec}$, and ATP $(0.5 \mathrm{~mm})$ was added at $300 \mathrm{sec}$. The data shown are from one of six independent experiments performed. $C$. The inactive PKC inhibitor peptide R27E-PKC and ATP $(0.5 \mathrm{~mm})$ was added at $300 \mathrm{sec}$ after starting recordings. The data shown are from one of four independent experiments performed. 


\section{A Control}



B +ATP
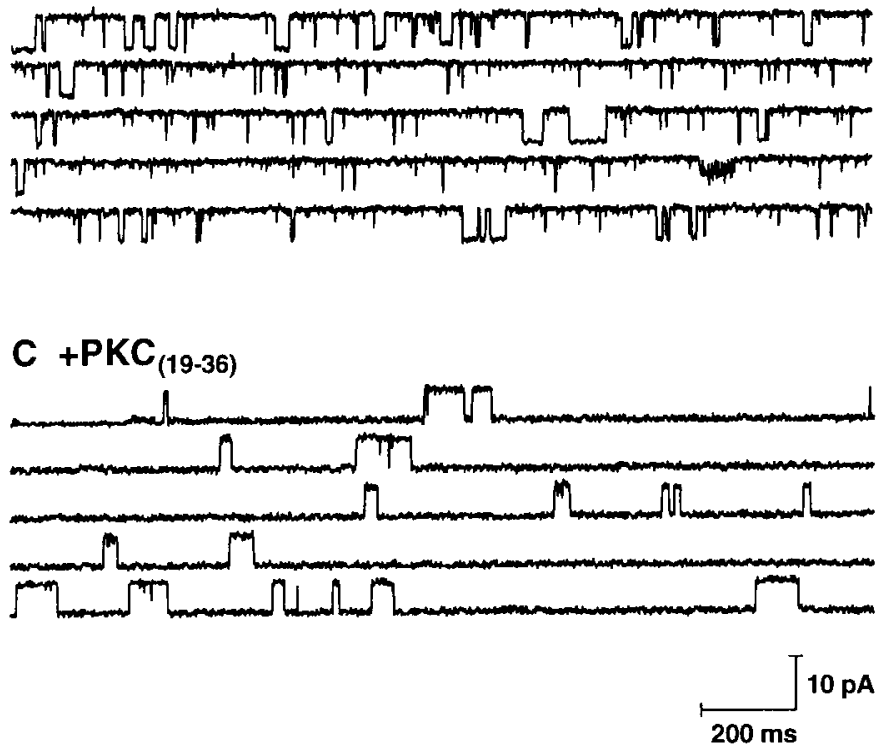

Figure 3. $\mathrm{PKC}_{113,36}$, reverses the ATP-induced upmodulation of type-2 large-conductance $\mathrm{Ca}^{2}{ }^{2}$-activated $\mathrm{K}^{+}$channels. A single type-2 $\mathrm{Ca}^{2+}$ activated $\mathrm{K}$ channel was incorporated into planar lipid bilayers as in Figure 1. For all traces channel openings are shown as upward deflections from the closed level current. $A$, Control. Single channel transitions just prior to the addition of ATP. $B$, +ATP. Single channel transitions $3 \mathrm{~min}$ after the addition of ATP $(0.5 \mathrm{~mm})$ to the cytoplasmic side of the channel. $C,+P_{K} C_{(y-z ; .}$. Single channel transitions $6 \mathrm{~min}$ after the addition of the PKC inhibitor peptide $\mathrm{PKC}_{1 /(4.36)}(0.2 \mu \mathrm{M})$ to the cytoplasmic side, in the continued presence of ATP. The data shown are from one of eight independent experiments performed.

\section{$P K C$ inhibition reverses the modulation by $P K C$}

To determine whether persistent protein kinase activity is required for the sustained increase in channel open probability produced by ATP, we added the PKC inhibitor after first upmodulating the channel with ATP (Figs. 3, 4). ATP causes a large increase in type-2 channel activity within several minutes after its addition (Figs. $3 A, B ; 4)$. Subsequent addition of $\mathrm{PKC}_{1, K_{1},}$, in the continued presence of ATP, reverses the modulation, and the channel activity declines to (or often below) control levels (Fig. 3C; eight of nine experiments). This is confirmed by an examination of the change in channel open probability as a function of time (Fig. $4 A$ ). The channel open probability declines rapidly after the addition of $\mathrm{PKC}_{(19-3 h)}$, suggesting that an endogenous phosphatase activity may reverse the effects of ATP when the endogenous kinase activity is inhibited. The reversal of the ATP modulation by $\mathrm{PKC}_{(19-3 \hbar)}$ does indeed result from inhibition of a PKC-like kinase, because $\mathrm{R} 27 \mathrm{E}-\mathrm{PKC} \mathrm{C}_{\left(1^{1}-3(6)\right.}$ does not produce this effect (Fig. $4 B$; four of four experiments).


\section{Time (min)}

Figure 4. Time course of $\mathrm{PKC}_{112-3,3}$, reversal of the ATP-induced upmodulation of type- $2 \mathrm{Ca}^{2}$-activated $\mathrm{K}^{+}$channels incorporated into planar lipid bilayers. The channel open probability was adjusted to between 0.05 and 0.15 using either $\mathrm{CaCl}_{2}$ or EGTA. Each vertical line represents the average for a $10.24 \mathrm{sec}$ sweep. A. ATP $(0.5 \mathrm{~mm})$ was added at 16 min and $\mathrm{PKC}_{1 \%-3 \mathrm{~m})}(0.2 \mu \mathrm{M})$ was added at $36 \mathrm{~min}$. The data shown are from one of eight independent experiments performed. $B, \operatorname{ATP}^{2}(0.5 \mathrm{mM})$ was added at $16 \mathrm{~min}$ and the inactive PKC inhibitor R27E-PKC $(19,36)(2$ $\mu \mathrm{M})$ was added at $36 \mathrm{~min}$. The data shown are from one of four independent experiments performed.

\section{Phosphatase inhibitors enhance the modulation by ATP}

The fact that $\mathrm{PKC}_{(19-36)}$ not only blocks but can also reverse the modulation by ATP, inplies that in the presence ol ATP, channel activity is determined by a balance between endogenous kinase and phosphatase activities. This hypothesis predicts that the effect of ATP should be enhanced by inhibiting the phosphatase activity. A submaximal concentration of ATP produces a modest increase in channel activity accompanied by fluctuations in open probability (Figs. 5, 6; and Chung et al.. 1991). Addition of microcystin-LR, a relatively non-specific inhibitor of phosphoprotein phosphatases, in the continued presence of ATP, increases the open probability further and tends to dampen the $\Lambda \mathrm{TP}$ induced oscillations (Fig. $5 ; n=6$ ). This increase in open prob- 


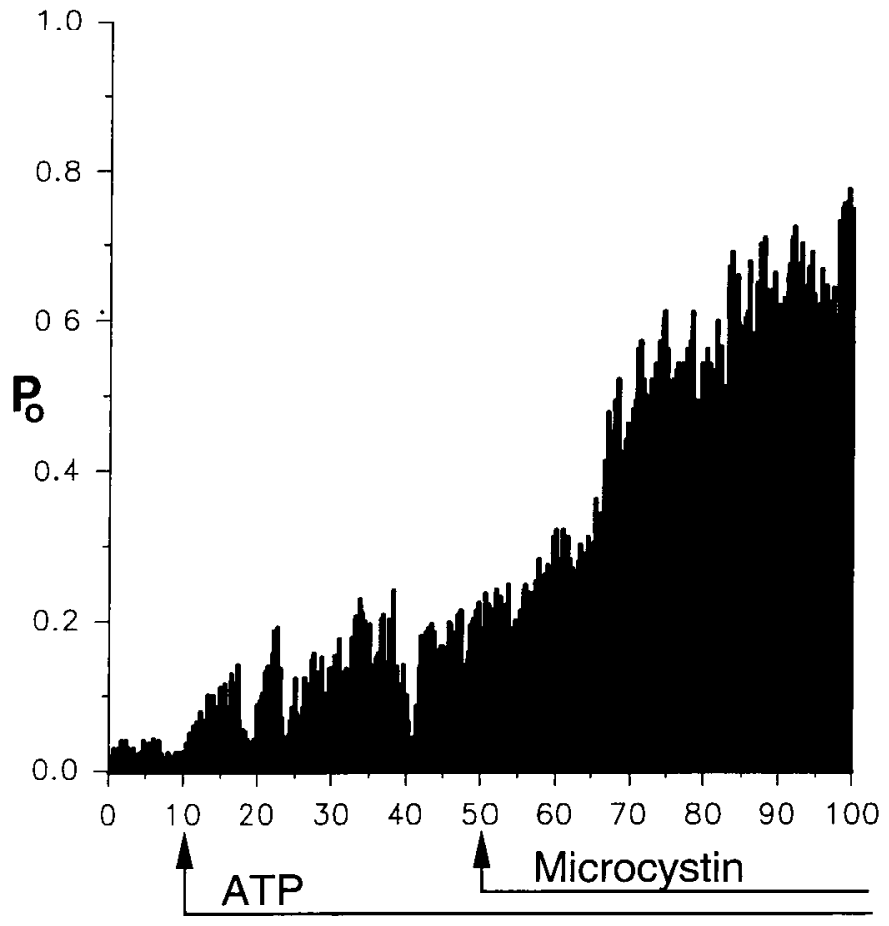

Time (min)

Figure 5. Microcystin enhances the ATP-induced upmodulation of type-2 $\mathrm{Ca}^{2+}$-activated $\mathrm{K}^{+}$channels. The ion channel open probability was adjusted to $0.02-0.05$ with EGTA, and ATP $(0.5 \mathrm{~mm})$ wats added at $10 \mathrm{~min}$. Microcystin-LR $(0.25 \mu \mathrm{M})$ was added at $50 \mathrm{~min}$. The data shown are from one of six independent experiments performed.

ability ranged from 1.7 - to 3.8-fold. In the absence of ATP microcystin does not alter channel activity $(n=4$; data not shown).

At the concentration of microcystin (250 nM) used in these experiments, the effect is to block predominantly phosphoprotein phosphatase-1 (PP-1) and phosphatase-2A (PP-2A), without significantly affecting phosphatases-2B or $-2 \mathrm{C}$ (MacKintosh et al., 1990). Okadaic acid, a structurally unrelated phosphatase inhibitor that is also relatively non-specific, also enhances the modulation of type- $2 \mathrm{~K}_{\mathrm{c}: \mathrm{i}}$ channels by ATP (1.5-3.1-fold increase in open probability, six of seven experiments; data not shown). To characterize in more detail the endogenous phosphatase activity associated with type- $2 \mathrm{~K}_{\mathrm{Ca}}$ channels, we utilized inhibitor-1 (I-1), a specific protein inhibitor of PP-1 (Shenolikar and Nairn, 1991; Nairn and Shenolikar, 1992). This $19 \mathrm{kDa}$ thermostable protein found in liver, muscle, and brain is active only when it is phosphorylated on the threonine residue at position 35 (Aitken et al., 1982; Stralfors et al., 1989); it can be dephosphorylated by phosphatases-2A and $-2 \mathrm{~B}$. To protect I-I against dephosphorylation during the course of these experiments, the protein was thiophosphorylated using the catalytic subunit of PKA and $\mathrm{ATP} \gamma \mathrm{S}$, since thiophosphorylated proteins are poor substrates for dephosphorylation by phosphoprotein phosphatases (Gratecos and Fischer, 1974). The modulation of type- $2 \mathrm{~K}_{\mathrm{Ca}}$ channel activity produced by a submaximal concentration of ATP (Fig. 6A), is markedly enhanced (1.9-4.6-fold) if the channel is pretreated with thiophosphorylated (and hence active) $\mathrm{I}-\mathrm{I}$ (Fig. $6 B ; n=3$ ). In addition, the fluctuations normally seen after Al'P treatment (e.g., Figs. 5, 6A) are largely abolished in the presence of I-1 (Fig. 6B). I-I alone does not
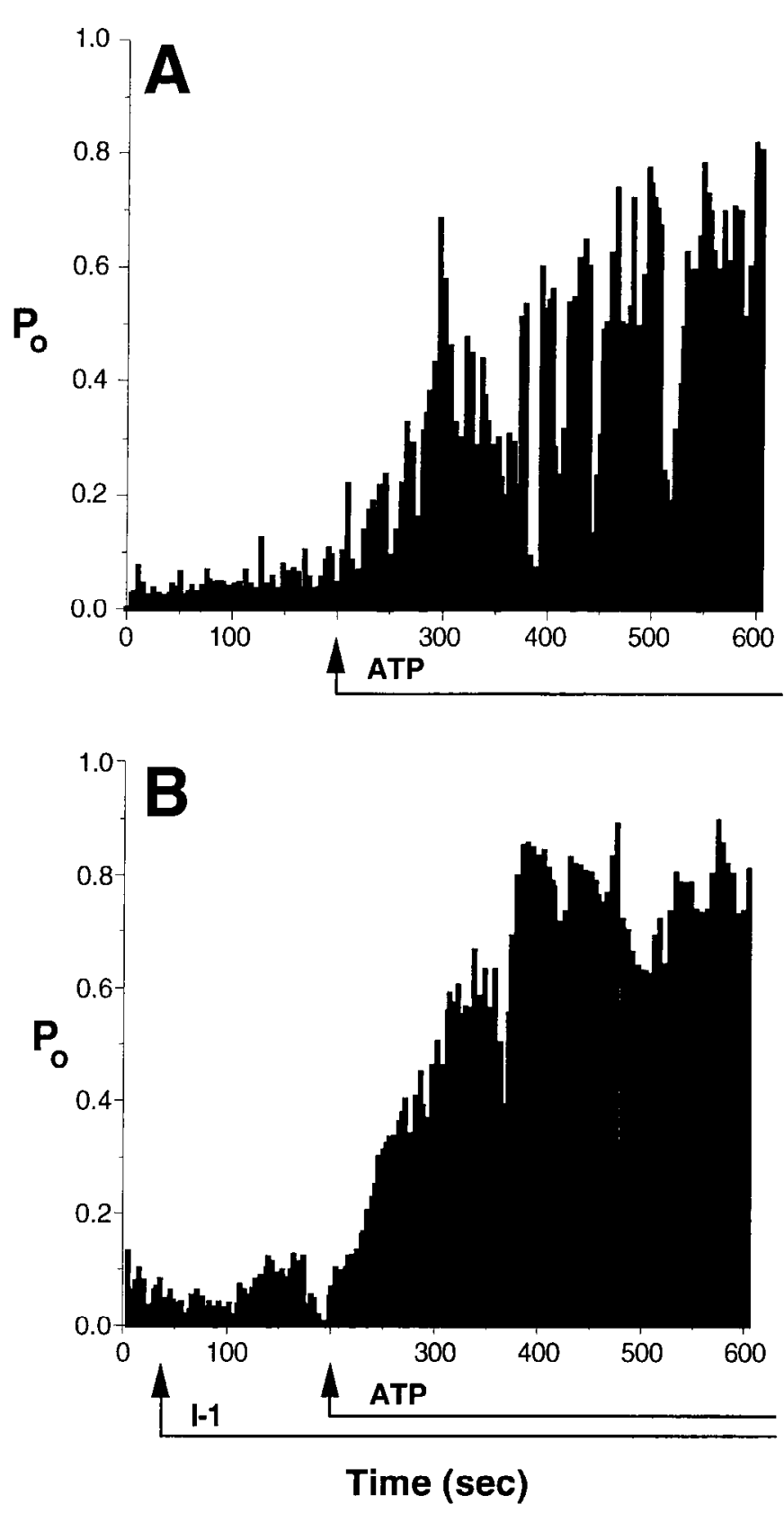

Figure 6. Inhibitor-1 potentiates the ATP-induced activation of type-2 $\mathrm{Ca}^{2+}$-activated $\mathrm{K}$ channels. The ion channel open probability was adjusted to a low starting value with EGTA. Each vertical line represents the average for a $5.12 \mathrm{sec}$ sweep. A. ATP $(0.5 \mathrm{~mm})$ was added at 200$)$ sec. $B$, Thiophosphorylated phosphatase inhibitor- $I(I-I, 80 \mathrm{~nm})$ was added at $30 \mathrm{sec}$, and ATP $(0.5 \mathrm{~mm})$ at $200 \mathrm{sec}$. The data shown are from one of three independent experiments performed. For the three experiments the average open probability under control conditions was $0.06 \pm 0.03$ (mean $\pm \mathrm{SD}$ ), and in the presence of ATP wals $0.51 \pm$ 0.24 (this increase is comparable to that seen with ATP in more than 50 other experiments). When ATP was added in the presence of I-I. the average open probability was $0.77 \pm 0.08$. This was significantly different from the value with ATP alone $(p<0.05$, one-waly ANOVA).

affect the activity of this channel in the absence of ATP ( $n=$ 3; data not shown). These results are consistent with the participation of an endogenous PP-1-like phosphoprotein phosphatase activity in the modulation of the type- $2 K_{c: 1}$ channel from rat brain. 


\section{Discussion}

$\mathrm{K}_{\mathrm{Ci}}$ channels are ubiquitously distributed in a wide variety of organisms and tissues, including the mammalian CNS (Latorre et al., 1989; McManus, 1991). Because they provide a link between the membrane potential and second messenger systems, regulation of their activity is critical for many cellular functions. Modulation of $\mathrm{K}_{\mathrm{Ca}}$ channels by protein phosphorylation and other mechanisms has been documented in several cell types (DePeyer et al., 1982; Ewald et al., 1985; Lechleiter et al., 1988; Sadoshima et al., 1988; Kume et al., 1989, 1992; Toro et al., 1990; White et al., 1991, 1993; Bielefeldt and Jackson, 1994a). In neurons, $K_{c:}$ channel modulation is likely to influence such essential functional properties as action potential frequency and neurotransmitter release (Lancaster et al., 1991; White et al., 1991; Robitaille and Charlton, 1992; Bielefeldt and Jackson, 1994a).

\section{Modulation by two protein kinases}

Although several cDNA's coding for $\mathrm{K}_{C \text { it }}$ channels have recently been cloned (Atkinson et al., 1991; Adelman et al., 1992; Butler et al., 1993; Tseng-Crank et al., 1994), we do not know the sequence of the type- $2 \mathrm{~K}_{\mathrm{Ca}}$ channel from rat brain. Nevertheless, from the experiments in planar bilayers, in which the channel protein is essentially at infinite dilution in the bilayer lipid, we can infer that this channel or some closely associated regulatory protein must contain phosphorylation sites for at least two distinct protein kinases. The open probability of the type- 2 channel can be decreased by exogenously added PKA (Reinhart et al., 1991), and increased by exogenous PKC (Fig. 1) and by an endogenous protein kinase (Chung et al., 1991) that we show here exhibits properties of $\mathrm{PKC}$. The results obtained here do not allow us to identify which of the many $\mathrm{Ca}^{2+}-$ sensitive and $\mathrm{Ca}^{2+}$-insensitive subspecies of PKC (Nishizuka et al., 1989; Lester and Bramham, 1993; Dekker and Parker, 1994) is involved.

There are other examples of regulation of an ion channel by several different protein kinases. For example, in $\mathrm{T}$ lymphocytes the modulation of delayed rectifier potassium channels by PKA is enhanced by phosphorylation with PKC (Payet and Dupuis, 1992). Similarly, in voltage-gated sodium channels that have becn cloned and expressed in a mammalian cell line, there is a requirement for $\mathrm{PKC}$ phosphorylation to allow modulation by PKA (Li et al.. 1993). Coregulation has also been observed for calcium channels in sensory neurons (Braha et al., 1993), chloride channels in ventricular myocytes (Walsh and Kong, 1994), and glycine receptors expressed in Xenopus oocytes (Vaello et al., 1994). Such convergent regulation of a single protein by two distinct second messenger systems implies that some ion channel proteins may act as a focus for integrating the input from different signaling pathways.

\section{A phosphatase activity intimately associated with the type-2 channel}

The fact that inhibition of the endogenous PKC-like kinase activity not only blocks but also reverses the modulation by ATP, is strong evidence for an ongoing dephosphorylation reaction that participates in the regulation of channel activity. Also consistent with this idea is the finding that the channel open probability undergoes large oscillations after treatment with ATP (e.g., Figs. 5, 6A; see also Chung et al., 1991), but not after treatment with ATP $\gamma \mathrm{S}$ (Chung et al., 1991). These data suggest that the oscillations in channel activity following ATP addition may reflect fluctuations in the balance between endogenous $\mathrm{ki}$ - nase and phosphatase activities; no oscillations are seen with ATP $\gamma \mathrm{S}$ because the thiophosphorylated proteins it produces are very poor substrates for phosphatases (Gratecos and Fisher. 1974). A role for an endogenous phosphatase in channel regulation is further confirmed by the finding that phosphatase inhibitors can enhance the action of ATP. Furthermore, the enhancement produced by I- 1 indicates that the endogenous phosphatase activity is PP-1-like. This is consistent with previous data showing that exogenously added PP- 1 can reverse the ATPmediated modulation of these type- 2 channels (Chung et al., 1991). Thus the kinase and phosphatase activities associated with type- $2 \mathrm{~K}_{\mathrm{Ca}}$ channels resemble, at least in some of their pharmacological properties, ubiquitous enzymes that participate in the regulation of many cellular properties in neurons and other cells (Byrne et al., 1993).

\section{A regulatory complex associated with type- $2 K_{c_{i n}}$ channels}

The present findings, together with those we have reported previously (Chung et al., 1991), provide strong evidence that type-2 $\mathrm{K}_{\mathrm{Cu}}$ channels exist as part of a regulatory complex that includes kinase and phosphatase activities both of which can regulate channel activity. Bielefeldt and Jackson (1994a,b) have also suggested a close association between type-2 channels and modulatory enzymes in membrane patches from posterior pituitary nerve terminals. We emphasize that such an association among channel, kinase, and phosphatase is the simplest mechanism consistent with these data. There is also evidence for more complicated biochemical cascades in channel modulation, including regulatory interactions between kinases and phosphatases themselves (White et al., 1993; Wilson and Kaczmarek, 1993). The oscillations in type-2 cliannel activity after ATP treatment often have a period of several minutes (e.g., Figs. 5, 6A; Chung et al., 1991). Presumably, the channel activity at any given time reflects its net phosphorylation state, and this in turn will depend on the balance between opposing kinase and phosphatase activities. We do not know what factors determine this balance, but the data on kinase/phosphatase cascades in channel regulation (White et al., 1993; Wilson and Kaczmarek, 1993) bring up the intriguing possibility that the kinase and phosphatase activities in a complex regulate each other.

In the case of type-2-like $\mathrm{K}_{\mathrm{Ca}}$ channels in nerve terminals from the posterior pituitary, a calculation based on the kinetics of modulation in membrane patches suggests that the channels are phosphorylated by an intramolecular reaction but dephosphorylated by an intermolecular reaction (Bielefeldt and Jackson, 1994b). This leads to the conclusion that the kinase (but not the phosphatase) involved in channel modulation is closely associated with the channel. Our experiments were carried out on channels reconstituted in phospholipid bilayers, in which channels and other proteins are essentially at infinite dilution, and hence both the endogenous kinase and phosphatase activities must be so intimately associated with the type- $2 \mathrm{~K}_{\mathrm{Ci}}$ channel that they diffuse with it in the bilayer (see note 12 in Chung et al., 1991, for the details of this argument). It is possible that the kinase and/or phosphatase activities reside in tightly bound subunits of the channel. A voltage-gated potassium channel, purified by its binding to the potassium channel toxin dendrotoxin, contains a protein kinase activity that may be intrinsic to a subunit that copurifies with the channel (Rehm et al., 1989). It is becoming evident that all voltage-gated ion channels, including potassium channels (Rettig et al,, 1994), have auxiliary subunits that modulate channel properties (Isom et al., 1994), and one of 
the functions of these auxiliary proteins may be to participate in the phosphorylation/dephosphorylation of the channels with which they are associated.

Another possibility is that the kinase and/or phosphatase activities are intrinsic to the ion channel protein itself. A search of potassium channel primary amino acid sequences provides no evidence for kinase or phosphatase catalytic domains. The $\mathbf{K}_{\mathrm{ca}}$ channel encoded by the Drosophila slowpoke locus does contain an ATP binding domain (Atkinson et al., 1991; Adelman et al., 1992) similar to that found in protein kinases, but the function of this domain remains to be determined. It is of interest that the Drosophila slowpoke $\mathrm{K}_{\mathrm{Ca}}$ channel, expressed in Xenopus oocytes, can be modulated by ATP $\gamma \mathrm{S}$ in the absence of exogenous protein kinases (Esguerra et al., 1994). This modulation results from phosphorylation of one particular serine residue in the channel protein, by a PKA-like protein kinase that remains functionally associated with the channel in detached membrane patches (Esguerra et al., 1994). Thus either the channel itself contains intrinsic kinase activity, or it can associate tightly with an endogenous kinase from a heterologous host cell in which it is not normally expressed. Both of these possibilities suggest that modulateability by phosphorylation and dephosphorylation is a fundamental property of $\mathrm{K}_{\mathrm{Cal}}$ and perhaps other ion channels.

\section{Note added in proof}

Recently, two other laboratories have also reported the cloning and sequencing of hlso (Pallanck and Ganetzky [Hum Mol Gen 3:1239-1243]; Dworetzky et al. [Mol Brain Res 27:189-193]).

\section{References}

Adelman JP, Shen K, Kavanaugh MP, Warren RA, Wu Y, Lagrutta A, Bond CT, North RA (1992) Calcium-activated potassium channels expressed from cloned complementary DNAs. Neuron 9:209-216.

Aitken A. Bilham T, Cohen P (1982) Complete primary structure of protein phosphatase- 1 from rabbit skeletal muscle. Eur J Biochem 126:253-246.

Atkinson NS, Robertson GA, Ganetzky B (1991) A component of calcium-activated potassium channels encoded by the Drosophila slo locus. Science 253:551-555.

Bielefeldt K, Jackson MB (1994a) Phosphorylation and dephosphorylation modulate a $\mathrm{Ca}^{2+}$-activated $\mathrm{K}$ channel in rat peptidergic terminals. J Physiol 475:241-254.

Bielefeldt K. Jackson MB (1994b) Intramolecular and intermolecular enzymatic modulation of ion channels in excised membrane patches. Biophys J 66:1904-1914.

Braha O, Sacktor T, Kandel ER, Klein M (1993) The contribution of protein kinase $A$ and protein kinase $C$ to the actions of 5-HT on the L-type $\mathrm{Ca}^{2}$ current of sensory neurons in Aplysia. J Neurosci 13: $1839-1851$

Butler A, Tsunoda S, McCobb DP, Wei A, Salkoff L (1993) mSlo, a complex mouse gene encoding "maxi" calcium-activated potassium channels. Science 261:221-224.

Byrne JH, Zwartjes R, Homayouni R, Critz SD, Eskin A (1993) Roles of second messenger pathways in neuronal plasticity and in learning and memory. Adv Second Messenger Res 27:47-108.

Catterall WA (1993) Structure and function of voltage-gated ion channels. Trends Neurosci 16:500-506.

Chung SK, Reinhart PH, Martin BL, Brautigan D, Levitan IB (1991) Protein kinase activity closely associatcd with a reconstituted calcium-activated potassium channel. Science 253:560-562.

Coronado R, Latorre $\mathrm{R}$ (1982) Detection of $\mathrm{Cl}$ - and $\mathrm{K}^{+}$channels in from calf cardiac sarcolemma in planar lipid bilayer membranes. Nature 298:849-852.

Dekker LV, Parker PJ (1994) Protein kinase C-a question of specificity. Trends Biol Sci 19:73-77.

DePeyer JE, Cachelin AB, Levitan IB, Reuter H (1982) $\mathrm{Ca}^{2+}$-activated $\mathrm{K}^{+}$conductance in internally perfused snail neurons is enhanced by protein phosphorylation. Proc Natl Acad Sci USA 79:4207-4211.

Esguerra M, Wang J, Foster CD, Adelman JP, North RA, Levitan IB
(1994) Cloned $\mathrm{Ca}^{2+}$-dependent $\mathrm{K}^{+}$channel modulated by a functionally associated protein kinase. Nature 369:563-565.

Ewald D, Williams A, Levitan IB (1985) Modulation of single Ca ${ }^{2+}$ dependent $\mathrm{K}^{+}$channel activity by protein phosphorylation. Nature 315:503-506.

Gratecos D, Fischer EH (1974) Adenosine 5'-0(3-thiotriphosphate) in the control of phosphorylase activity. Biochem Biophys Res Commun 58:960-967.

Isom LL, DeJongh KS, Catterall WA (1994) Auxiliary subunits of voltage-gated ion channels. Neuron 12:1183-1194.

Kume $\mathrm{H}$, Tokuno $\mathrm{H}$, Tomita $\mathrm{T}$ (1989) Regulation of $\mathrm{Ca}^{2+}$-dependent $\mathrm{K}^{+}$-channels in tracheal myocytes by phosphorylation. Nature 341 : $152-154$

Kume H, Graziano MP. Kotlikoff MI (1992) Stimulatory and inhibitory regulation of calcium-activated potassium channels by guanine nucleotide-binding proteins. Proc Natl Acad Sci USA 89:11051-11055.

Lancaster B, Nicoll RA, Perkel DJ (1991) Calcium activates two types of potassium channels in rat hippocampal neurons in culture. J Neurosci 1 1:23-30.

Latorre R, Oberhauser A, Labarca P, Alvarez O (1989) Varieties of calcium-activated potassium channels. Annu Rev Physiol 51:385399.

Lechleiter ID, Dartf DA, Brehm P (1988) Vasoactive intestinal peptide activates $\mathrm{Ca}^{2+}$-dependent $\mathrm{K}^{+}$channels through a cAMP pathway in mouse lacrimal cells. Neuron 1:227-235.

Lester DS, Braham CR (1993) Pcrsistent, membrane associated protein kinase $\mathrm{C}$ : from model membranes to synaptic long-term potentiation. Cell Signal 5:695-708.

Levitan IB (1994) Modulation of ion channels by protein phosphorylation and dephosphorylation. Annu Rev Physiol 56:193-212.

Li M, West JW, Numann R, Murphy BJ, Scheuer T. Catterall WA (1993) Convergent regulation of sodium channels by protein kinase $\mathrm{C}$ and cAMP-dependent protein kinase. Science 261:1439-1442.

MacKintosh C, Beattie KA, Klumpp S, Cohen P, Codd GA (1990) Cyanobacterial microcystin-LR is a potent and specitic inhibitor of protein phosphatase- 1 and $2 \mathrm{~A}$ from both mammals and higher plants. ГEBS Lett 264:187-192.

McManus OB. (1991) Calcium-activated potassium channels: regulation by calcium. J Bioenerg Biomembr 23:537-560

Miller C (1986) Ion channel reconstitution. New York: Plenum.

Nairn AC, Shenolikar S (1992) The role of protein phosphatases in synaptic transmission, plasticity and neuronal development. Curr Opin Neurobiol 2:296-301

Nishizuka Y (1989) The family of protein kinase $C$ for signal transduction. J Am Med Assoc 262:1826-1833.

Payet MD, Dupuis G (1992) Dual regulation of the n type $\mathrm{K}$ ' channel in jurkat $T$ lymphocytes by protein kinases $A$ and $C$. $\mathbf{J}$ Biol Chem 267: 18270-18273.

Raymond LA, Blackstone CD, Huganir RL (1993) Phosphorylation of amino acid neurotransmitter receptors in synaptic plasticity. Trends Neurosci 16:147-153.

Rehm H, Pelzer S, Cochet C, Chambaz E, Tempel BL, Trautwein W. Pelzer D, Lazdunski M (1989) Dendrotoxin-binding brain membrane protein displays a $\mathrm{K}^{+}$channel activity that is stimulated by both cAMP-dependent and endogenous phosphorylations. Biochemistry 28:6455-6460.

Reinhart PH, Chung S, Levitan IB (1989) A family of calcium-dependent potassium channels from rat brain. Neuron 2:1031-1041.

Reinhart PH, Clung SK, Martin BL, Brautigan DL, Levitan IB (1991) Modulation of calcium-activated potassium channels from rat brain by protein kinase $A$ and phosphatase $2 \mathrm{~A}$. J Neurosci 1 1:1627-16.35.

Rettig J, Heinemann SH, Wunder G, Lorra C, Parcej DN. Dolly JO, Pongs $\mathrm{O}$ (1994) Inactivation properties of voltage-gated $\mathrm{K}^{+}$channels altered by presence of $\beta$-subunit. Nature 369:289-294.

Robitaille R, Charlton MP (1992) Presynaptic calcium signals and transmitter release are modulated by calcium-activated potassium channels. J Neurosci 12:297 305.

Sadoshima J, Akaike N, Kanaide H, Nakamura M (1988) Cyclic AMP modulates Ca-activated $\mathrm{K}$ channel in cultured smooth muscle cells of rat aortas. Am J Physiol 255:H754-H759.

Shenolikar S, Nairn AC (1991) Protein phosphatases: recent progress. Adv Second Messenger Res 23:1-121.

Stralfors P, Hemmings HC Jr, Greegard P (1989) Inhibitors of protein phosphatase-1. Inhibitor- 1 of bovine adipose tissue and a dopamine- 
and cAMP-regulated phosphoprotein of bovine brain are identical. Eur J Biochem 180:143-148.

Toro L, Ramos-Franco J, Stefani E (1990) GTP-dependent regulation of myometrial $K_{1, a}$ channels incorporated into lipid bilayers. $J$ Gen Physiol 96:373-394.

Tseng-Crank, J, Foster CD, Krause JD, Mertz R, Godinot N, DiChiara TJ, Reinhart PH (1994) Cloning, expression and distribution of functionally distinct $\mathrm{Ca}^{2+}$-activated $\mathrm{K}^{+}$channel isoforms from human brain. Neuron 13:1-20.

Vaello ML, Ruiz-Gomez A, Lerma J, Mayor F (1994) Modulation of inhibitory glycine receptors by phosphorylation by protein kinase $\mathrm{C}$ and cAMP-dependent protein kinase. J Biol Chem 269:2002-2008

Walsh KB, Kong KJ (1994) Properties of a protein kinase C-activated chloride current in guinea pig ventricular myocytes. Circ Res 74:121129
Wang G, Thorn P, Lemos JR (1992) A novel large-conductance $\mathrm{Ca}^{2}$ activated potassium channel and current in nerve terminals of the rat neurohypophysis. J Physiol (Lond) 457:47-74.

White RE, Schonbrunn A, Armstrong DL (1991) Somatostatin stimulates $\mathrm{Ca}^{2+}$-activaled $\mathrm{K}$ ' channels through protein dephosphorylation. Nature 351:570-573.

White RE, Lee AB, Shcherbatko AD, Lincoln TM, Schonbrunn A, Armstrong DL (1993) Potassium channel stimulation by natriuretic peptides through cGMP-dependent dephosphorylation. Nature 361: 263-266.

Wilson GF, Kaczmarek LK (1993) Mode-switching of a voltage-gated cation channel is mediated by a protein kinase A-regulated tyrosine phosphatase. Nature 366:433-438.

Woodgett JR, Hunter T (1987) Isolation and characterization of two distinct forms of protein kinase C. J Biol Chem 262:4836-4843. 